\title{
Эффекты ионной бомбардировки в спектрах краевой фотопроводимости и в вольт-амперных характеристиках кристаллов CdS
}

\author{
(C) А.С. Батырев ${ }^{1}$, Р.А. Бисенгалиев ${ }^{1, \uparrow}$, В.Н. Горяева ${ }^{1}$, Б.В. Новиков ${ }^{2}$, Е.В. Сумьянова ${ }^{1}$ \\ ${ }^{1}$ Калмыцкий государственный университет им. Б.Б. Городовикова, \\ 358000 Элиста, Россия \\ ${ }^{2}$ Санкт-Петербургский государственный университет, \\ 199034 Санкт-Петербург, Россия \\ ฯ E-mail: task99@mail.ru
}

Поступила в Редакцию 26 мая 2021 г.

В окончательной редакции 29 мая 2021 г.

Принята к публикации 29 мая 2021 г.

Исследовано влияние ионной бомбардировки, производимой на воздухе, на электрические и фотоэлектрические свойства кристаллов $\mathrm{CdS}$ при температуре кипения жидкого азота $(T=77 \mathrm{~K})$. Показано, что бомбардировка кристаллов приводит к существенному росту фоточувствительности в области края поглощения, а также к росту их темновой проводимости. При этом количественные изменения в темновой проводимости значительно превосходят изменения в фоточувствительности всех исследованных образцов. Наблюдаемые изменения тонкой (экситонной) структуры свидетельствуют о поверхностном характере воздействия ионов на полупроводник. Обнаруженные изменения связываются с поверхностным легированием исследуемых полупроводников донорами с помощью ионной бомбардировки. Применяемая методика бомбардировки может быть использована в практических целях с целью модификации электрических свойств полупроводников, принадлежащих к соединениям $\mathrm{A}^{\mathrm{II}} \mathrm{B}^{\mathrm{VI}}$.

Ключевые слова: ионная бомбардировка, спектры фотопроводимости, кристаллы CdS, вольт-амперная характеристика, тонкая структура.

DOI: 10.21883/FTP.2021.11.51554.9687

\section{1. Введение}

Исследование влияния внешних поверхностно-чувствительных воздействий на поверхность полупроводников позволяет изучать механизмы формирования процессов, ответственных за основные электрические, оптические и фотоэлектрические свойства материалов. Одним из таких воздействий является ионная бомбардировка (ИБ) полупроводников. Исследованию ИБ посвящено достаточно большое число работ (см., например, [1,2]). ИБ полупроводников, как метод воздействия, уже используется достаточно давно и имеет широкое научноприкладное значение. Например, такое внешнее воздействие позволяет контролируемо модифицировать свойства приповерхностных слоев кристаллов, что отражается на их общих эксплуатационных характеристиках. Вместе с тем влияние ИБ на свойства прямозонных кристаллов группы $\mathrm{A}^{\mathrm{II}} \mathrm{B}^{\mathrm{VI}}$ изучено не так широко, притом что, как было обнаружено, ИБ приводит к проявлению значительных изменений в электрических и фотоэлектрических свойствах исследуемых материалов. В работе [3] сообщается об эффектах ионно-аргонной бомбардировки в краевых спектрах фотопроводимости (ФП) кристаллов $\mathrm{CdS}$ при комнатной температуре, где исследованы изменения в спектральном распределении фототока, а также вольт-амперных характеристик (BАХ) полупроводников после ИБ.
В данной работе исследуется влияние ИБ на спектры ФП кристаллов $\mathrm{CdS}$ в краевой области поглощения и на равновесную (темновую) проводимость при низкой $(77 \mathrm{~K})$ температуре. Изучение наблюдаемых эффектов основано на исключительно высокой чувствительности экситонных состояний, возбуждаемых в области края поглощения, на различные внешние поверхностно-чувствительные воздействия.

\section{2. Методы}

Измерения выполнены на „чистых“, специально не легированных, монокристаллах $\mathrm{CdS}$, выращенных газотранспортным методом из газовой фазы (методом Фрерихса) [4]. Исследуемые образцы представляли собой пластинки, толщина которых варьировалась в интервале 10-100 мкм. Площадь больших граней пластинок не

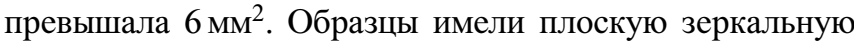
поверхность, которая являлась естественной гранью кристалла. Длина образцов составляла несколько миллиметров. Темновое удельное сопротивление исследуемых кристаллов при комнатной температуре составляло $10^{10}-10^{12} \mathrm{Oм} \cdot \mathrm{cm}$. Измерения выполнены на нескольких образцах кристаллов $\mathrm{CdS}$, принадлежащих к 1-й и 2-й группам тонкой (экситонной) структуры [5]. Полученные результаты для всех исследованных образцов 


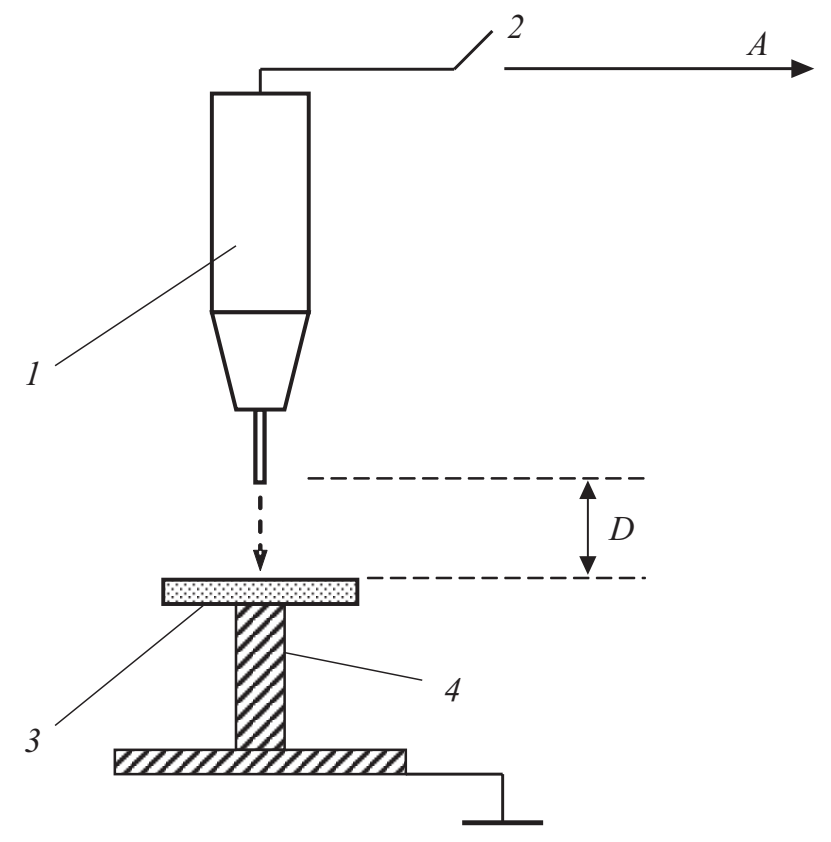

Рис. 1. Схема ионной бомбардировки: 1 - высокочастотный индуктор „Тесла“, 2 - выключатель, 3 - образец кристалла $\mathrm{CdS}, 4$ - металлический столик; $D$ - расстояние между образцом и электродом индуктора; $A-$ подключение к электрической сети.

качественно согласуются между собой, отличаясь лишь количественно.

ФП возбуждалась излучением, выделяемым монохроматором МДР-3 из сплошного спектра светоизмерительной лампы накаливания СИ-10-300у. Спектральная ширина щели монохроматора не превышала $8 \AA$. Спектры ФП измерялись в области края фундаментального поглощения при температуре кипения жидкого азота $(T=77 \mathrm{~K})$. Напряжения, прикладываемые к образцам, составляли значение, порядка нескольких десятков вольт. Спектры измерялись в поляризации $E \perp c, k \perp c$, где $E-$ электрический, а $k-$ волновой вектор световой волны, $c$ - гексагональная ось кристалла. Токоподводящие контакты создавались с помощью In-Ga пасты, которая наносилась на поверхность полупроводниковой пластинки с противоположных ее сторон. Расстояние между контактами составляло 2-3 мм. Регистрация спектров стационарного возбуждения ФП осуществлялась с помощью электрометрического усилителя У5-9, регистрирующего значения тока в диапазоне $10^{-10}-10^{-4} \mathrm{~A}$. Спектры ФП автоматически записывались на ленте самопишущего потенциометра КСП-4. Величина фототока для всей партии исследованных образцов варьировалась от $10^{-7}$ до $10^{-6} \mathrm{~A}$. Наряду со спектрами ФП также измерялась равновесная (темновая) проводимость образцов. Для измерения равновесной проводимости измерялся ток, текущий через исследуемый образец, в отсутствии его освещения при фиксированных приложенных напряжениях. В этом случае величина тока, текущего через полупроводник, достигала максимальных значений $\sim 10^{-4} \mathrm{~A}$.

Внешнее воздействие на исследуемые образцы производилось на воздухе за счет ИБ поверхности кристалла с помощью высокочастотного индуктора типа „Тесла“, генерирующего искровой разряд при его включении. Создание разряда осуществлялось при расположении электрода индуктора на расстоянии $D$ от образца, которое не превышало 5 мм. В противном случае разряд не генерировался. Схема ионной бомбардировки образца приведена на рис. 1. Образец (3) крепился к металлическому столику (4), который представлял собой медный провод с поперечным сечением $\sim 2 \mathrm{Mм}^{2}$. Площадь образца превышала площадь сечения провода. На поверхность столика предварительно была нанесена $\mathrm{In}-\mathrm{Ga}$ паста. Металлический столик (4) заземлялся. Искровой разряд создавался между электродом индуктора и металлическим столиком, при этом бомбардируя ионами образец. Время бомбардировки составляло несколько секунд. После облучения образец снова устанавливался в ячейку для спектральных измерений.

\section{3. Результаты}

Как показано в работе [6], в спектрах ФП монокристаллов $\mathrm{CdS}$ при низких температурах в окрестности края поглощения можно наблюдать тонкую структуру (TC), связанную с проявлением экситонных состояний. ТC проявляется в виде узких максимумов или минимумов фототока на резонансных частотах экситонов. Деление ТС на две группы было впервые осуществлено в работе [5]. К первой группе принадлежат кристаллы, в которых резонансные частоты экситонов совпадают со спектральным положением максимумов, а ко второй минимумов фототока.

Для иллюстрации наблюдаемого эффекта на рис. 2 представлены низкотемпературные спектры краевой ФП одного из исследованных образцов кристалла $\mathrm{CdS}$. В исходном состоянии (до облучения) в спектре проявляется ТС второго типа [5], где линиям поглощения экситонов, спектральные положения которых обозначены стрелками $A, B$ и $C$, соответствуют минимумы фототока (кривая 1). С длинноволновой стороны края поглощения, в спектральной области $\sim 492$ нм, проявляется слабовыраженный дополнительный максимум фототока „примесной“ природы [7,8] ( $I_{1}$ в обозначениях [9]).

Как показал эксперимент, облучение образца кристалла CdS ионами, в течение некоторого времени $t$, приводит к его „очувствлению“ (см. масштабный множитель на рис. 2), при этом изменяя структуру спектра фототока в области экситонного поглощения. Так, при облучении кристалла в течение $t=5 \mathrm{c}$ (кривая 2) наблюдается „очувствление“ кристалла и полное сглаживание экситонной структуры. Повышение общего времени облучения до $t=10$ с (кривая 3) приводит к дальнейшему 


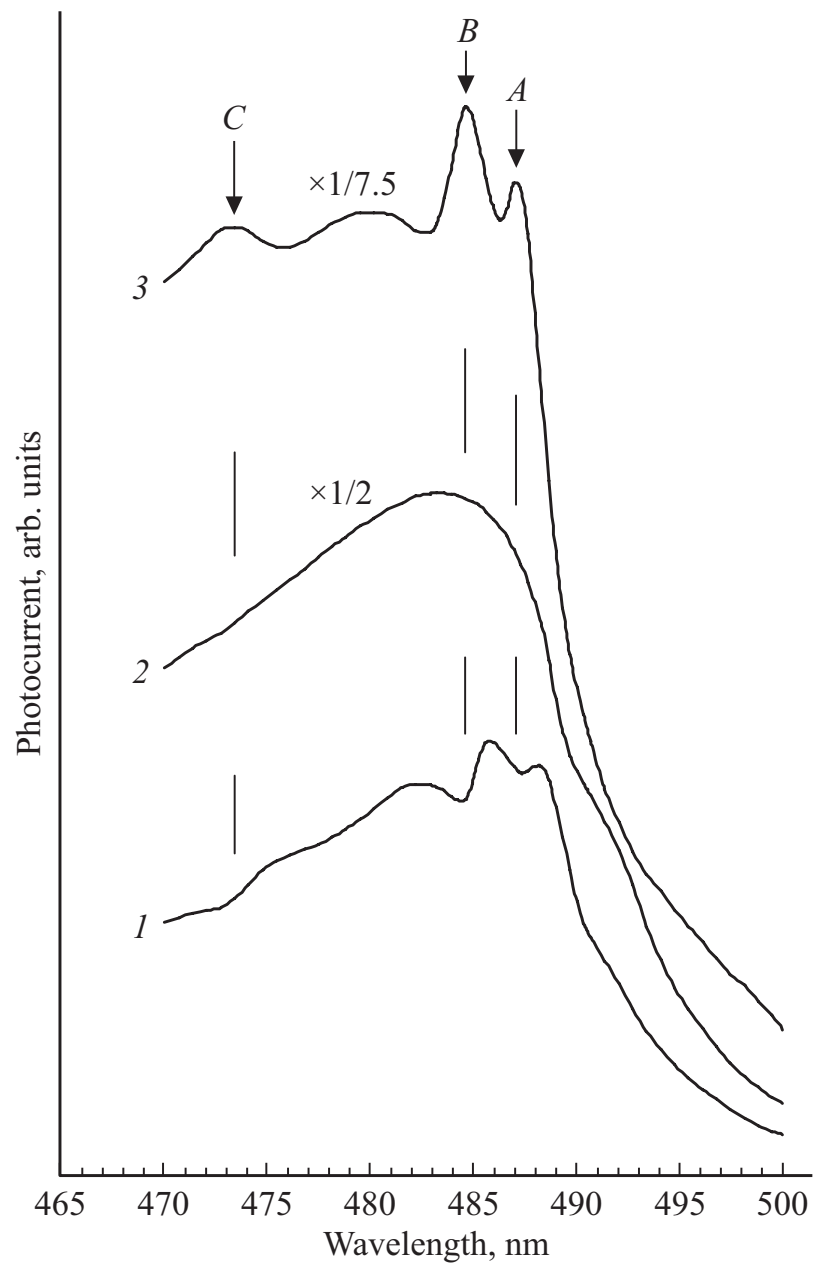

Рис. 2. Спектры краевой фотопроводимости кристалла $\mathrm{CdS}$ (образец BK-Q-II), измеренные в исходном состоянии (1) и подвергнутого облучению ионами в течение $t=5$ (2) и $10 \mathrm{c}(3)$.

„очувствлению“ образца и к трансформации ТС фототока в первый тип, где линиям поглощения экситонов уже соответствуют узкие максимумы фототока [6]. Следует обратить внимание на селективность эффекта: рост фоточувствительности (ФЧ) полупроводника после ИБ создается преимущественно в коротковолновой области спектра от края поглощения, в то время как на длинноволновом спаде спектра ФЧ возрастает относительно слабо. При больших временах облучения (несколько десятков секунд) рост ФЧ выходит на насыщение и практически уже не изменяется.

Как было сказано ранее, ИБ кристаллов типа $\mathrm{CdS}$, приводит не только к изменениям в спектрах ФП, но и в их равновесной (темновой) проводимости $\sigma$. На рис. 3 приведена ВАХ одного из исследованных образцов до (кривая 1) и после ИБ (кривые 2 и 3) в течение времени $t$. Из рис. 3 видно, что ИБ приводит к сильному изменению угла наклона ВАХ, что свидетельствует о значительном увеличении $\sigma$ по мере роста времени $t$ ее воздействия на поверхность кристалла (см. масштабный множитель на рис. 3).

Приведенные ВАХ измерены при последовательном нарастании приложенного к полупроводнику напряжения. Отметим, что после ИБ ход ВАХ при последовательном нарастании и понижении приложенного напряжения заметно отличается. Такое отличие BAX постепенно исчезает с течением длительного времени (до нескольких суток) после ИБ, и после длительной выдержки образца полевое поведение ВАХ становится почти независимым от направления изменения напряжения. Аналогичное поведение ВАХ после ИБ демонстрировали все исследованные образцы.

Ярким эффектом ИБ является различная скорость роста величины темнового тока и фототока при различных временах облучения образца $t$ (рис. 4). Для примера приведены экспериментальные данные для трех исследованных образцов окристалла CdS. Согласно полученным данным (рис. 4), темп роста величины фототока $I_{\mathrm{B}}$ и темнового тока $I_{0}$ при различных временах облучения образцов $t$ отличается между собой на несколько порядков величины и является общей характерной чертой для всех исследованных образцов и не зависит от типа ТС

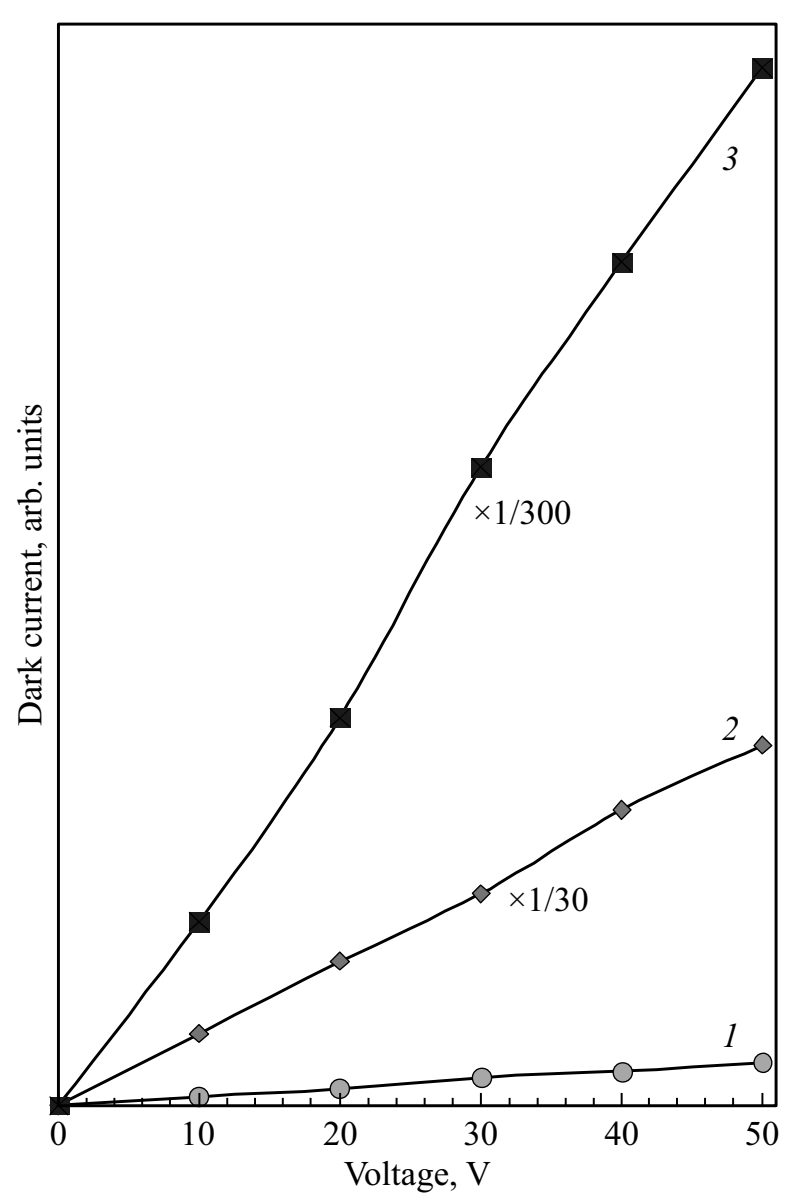

Рис. 3. Вольт-амперная характеристика кристалла $\mathrm{CdS}$ (образец BK-Q-II), измеренная в исходном состоянии (1) и после его облучения ионами в течение $t=5$ (2) и $10 \mathrm{c} \mathrm{(3).}$ 


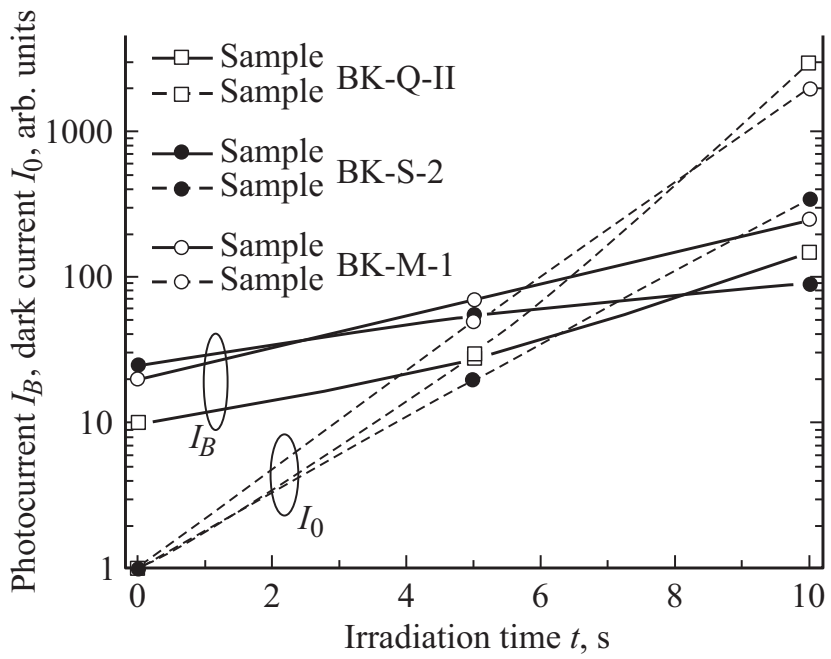

Pис. 4. Значения фототока $I_{B}$, измеренного на частоте $B$ экситона, и темнового тока $I_{0}$ для разных образцов кристалла $\mathrm{CdS}$ после их облучения ионами в течение времени $t$.

спектра ФП исходного образца и его исходной удельной темновой проводимости.

Как было обнаружено, индуцируемые ИБ спектральные характеристики, а также темновая проводимость образцов не остаются постоянными во времени. Выдержка образцов в течение определенного времени (до нескольких суток) приводит к понижению ФЧ и темновой проводимости образцов по сравнению с их значениями, полученными сразу после бомбардировки. Для большинства исследованных образцов $\mathrm{CdS}$ такое понижение составляло примерно от 10 до $40 \%$ от значений, измеренных сразу после ИБ. Как показал эксперимент, основное падение исследуемых параметров наблюдается в первые несколько суток (до 3-5 суток), а затем их понижение практически прекращается, устанавливаясь на определенных постоянных значениях, которые в любом случае превышают значения исходных данных.

Эксперименты на кристаллах $\mathrm{CdS}$, которые в исходном состоянии обладали первым типом ТС, показали, что ИБ приводит к аналогичным изменениям в ФЧ и в темновой проводимости образца, что и для кристаллов, обладающих вторым типом ТС, т.е. приводила к значительному их повышению. Однако при воздействии ионов на поверхность таких образцов ТС в спектре ФП первого типа полностью сглаживалась и в области экситонных состояний наблюдалась гладкая, бесструктурная кривая фототока.

С ростом длительности ионного облучения кристаллов $\mathrm{CdS}$ (до нескольких десятков секунд), кроме изменений в темновой проводимости, в спектре начинает проявляться эффект роста ФЧ вблизи краевой области „примесной“ фотопроводимости $(\lambda \approx 492-495$ нм $)$, которая, согласно данным работ $[7,8]$, связана с объемными свойствами полупроводника. Такое поведение спектров проявлялось в ряде образцов $\mathrm{CdS}$, подвергнутых длительной ИБ. При этом в экспериментах использовались кристаллы, обладающие в исходном состоянии ТС первого типа.

Отметим, что при больших временах облучения (до нескольких минут) темновая проводимость $\mathrm{CdS}$ возрастала настолько, что измерить необходимые электрические и спектральные характеристики облученного образца на используемом в эксперименте оборудовании уже не представлялось возможным.

\section{4. Обсуждение}

Как известно, экситонные состояния обладают высокой чувствительностью к различным поверхностночувствительным воздействиям [6]. Поэтому их можно использовать для диагностики состояния приповерхностной области полупроводника. Согласно данным работы [10], в полупроводниках с прямыми разрешенными переходами за счет высокого коэффициента поглощения в спектральной области экситонных и межзонных переходов, достигающего значений порядка $10^{5} \mathrm{~cm}^{-1}$, генерация экситонов происходит в тонком приповерхностном слое (в кристаллах $\mathrm{CdS}$ в слое толщиной $\sim 10^{-5} \mathrm{~cm}$ ). Соответственно, это приводит к зависимости ТС спектров ФП от внешних и внутренних факторов, возмущающих состояние поверхности и (или) приповерхностной области полупроводника.

Согласно работе [11], кристаллы CdS 1-й группы, выращенные по технологии [4], характеризуются наличием в приповерхностной области кристалла толщиной $\sim 100 \AA$, высокой концентрации (до $10^{18} \mathrm{~cm}^{-3}$ ) сверхстехиометрических межузельных атомов кадмия $\left(\mathrm{Cd}_{i}\right)$, играющих роль мелких (водородоподобных) доноров. Это приводит к обогащению приповерхностной области кристалла основными носителями (электронами) и проявлению ТС первого типа. Так как ИБ трансформирует ТC фототока из второго типа в первый (см. рис. 2), то полученные результаты позволяют сделать вывод о том, что изменения, вызванные ИБ, связаны с поверхностным легированием приповерхностной области кристалла донорными центрами, приводящими к созданию сильного обогащения основными носителями вблизи поверхности полупроводника. Напомним, что экситонные состояния генерируются вблизи поверхности и формируют ТС спектров ФП исследуемых полупроводников. О появлении высокой концентрации мелких донорных центров свидетельствует значительный рост темнового тока полупроводника после ИБ. При этом примесная ФП, связанная с объемом, изменяется относительно слабо (см. рис. 2). В связи с этим можно заключить, что при малых временах ИБ создание донорных состояний происходит в области, толщиной не менее $10^{-5} \mathrm{~cm}$, захватывающей область эффективной генерации экситонов.

В работе [12] произведен расчет формы спектральных кривых ФП кристаллов $\mathrm{CdS}$ при низких температурах 
для области экситонного поглощения. Согласно данным работы [12], спектральным кривым ФП первого типа отвечают обогащающие (положительные), а спектральным кривым второго типа - слабообогащающие либо обедняющие (отрицательные) поля на поверхности полупроводника. Согласно расчету, приведенному в работе [12], для положительных полей, формирующих ТС первого типа, величина напряженности приповерхностного поля $E_{S}>10^{2} \mathrm{~B} / \mathrm{cm}$. Промежуточным кривым со сглаженной ТС соответствуют почти плоские зоны.

Длительное воздействие ионного потока на поверхность образца способствует более глубокому проникновению ионов в полупроводник и, как следствие, созданию донорных центров уже на гораздо большей глубине от поверхности облучаемого образца. Это и создает основные условия для формирования роста

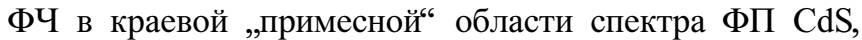
которая связывается с объемом полупроводника $[7,8]$. Отметим, что наряду с этим длительное воздействие ионного потока на поверхность $\mathrm{CdS}$ приводит также и к сглаживанию ТC первого типа, которая была в исходном состоянии исследуемых кристаллов. Для объяснения такого поведения необходимо воспользоваться моделью электронно-дырочного экранирования, представленной в работе [13]. Согласно данным работы [13], основным условием сглаживания ТС первого типа является наличие высокой концентрации основных носителей заряда в приповерхностной области полупроводника, которое в работе [13] создавалось с помощью метода эффекта поля. Действительно, с ростом длительности ионного облучения, кроме более глубокого проникновения ионов в полупроводник, вблизи поверхности создается такая концентрация доноров, которая способствует появлению сильного обогащения основными носителями. В итоге это приводит к трансформации ТС спектра ФП первого типа в бесструктурную спектральную кривую.

В качестве донорных центров, появляющихся в приповерхностной области кристалла после ИБ, по нашему мнению, являются собственные дефекты решетки типа межузельного кадмия $\left(\mathrm{Cd}_{i}\right)$ [14]. Эти центры могут создаваться за счет разупорядочивания кристаллической решетки при ее взаимодействии с высокоэнергетическими ионами воздуха, создаваемыми электрическим полем в промежутке кристалл - электрод индуктора. Также мелкие донорные центры способны появляться за счет внедрения атомов металла, из которого изготовлен электрод индуктора, в приповерхностную область кристалла. Действительно, во время облучения образец подвергался воздействию ионами воздуха, а также ионами, которые испаряются в момент электрического разряда из электродов индуктора. Состав электродов индуктора включает различные химические элементы, преимущественно различные металлы.

Незначительное ослабление эффекта ИБ при выдержке кристаллов в течение некоторого времени, отражающееся в виде понижения ФЧ образцов и их темновой проводимости, на наш взгляд, связано с различными релаксационными процессами на поверхности и в приповерхностной области полупроводника, приводящими к переходу неравновесных дефектов, созданных ИБ, к термодинамически равновесному состоянию кристаллической решетки.

\section{5. Заключение}

Проведенные исследования показали, что поверхностное легирование полупроводника донорными центрами, которое может создаваться с помощью ИБ, кардинально изменяет его спектральные и электрические характеристики. Представленная методика ИБ может быть использована в практических целях для контролируемого изменения свойств полупроводниковых материалов, принадлежащих к группе соединений $\mathrm{A}^{\mathrm{II}} \mathrm{B}^{\mathrm{VI}}$.

\section{Конфликт интересов}

Авторы заявляют, что у них нет конфликта интересов.

\section{Список литературы}

[1] И.А. Аброян. УФН, 104 (1), 15 (1971).

[2] А.И. Поплавский, А.Я. Колпаков, М.Е. Галкина, И.В. Суджанская, И.Ю. Гончаров, Е.Н. Бондарева. Науч. ведомости БелГУ. Сер.: Математика. Физика, № 23 (142), вып. 29, 177 (2012).

[3] А.С. Батырев, Р.А. Бисенгалиев, Т. Нурметов, С.С. Саргинов, Е.В. Сумьянова, Н. Халиков. Тенденции развития науки и образования. Самара. № 48, часть 5, 82 (2019).

[4] R. Frerichs. Phys. Rev., 72, 594 (1947).

[5] Е.Ф. Гросс, Б.В. Новиков. ФТТ, 1 (3), 357 (1959).

[6] В.А. Киселев, Б.В. Новиков, А.Е. Чередниченко. Экситонная спектроскопия приповерхностной области полупроводников (СПб., Изд-во СПбГУ, 2003).

[7] А.С. Батырев, Э.Д. Батырев, Р.А. Бисенгалиев, Б.В. Новиков, В.С. Анбушинов. ФТТ, 41 (7), 1181 (1999).

[8] А.С. Батырев, Р.А. Бисенгалиев, О.Э. Ботов, Н.В. Карасенко, Б.В. Новиков, Е.В. Сумьянова. ФТТ, 40 (5), 941 (1998).

[9] J.A. Bragagnolo, G.M. Storti, K.W. Boer. Phys. Status Solidi A, 22, 639 (1974).

[10] J. Voigt, E. Ost. Phys. Status Solidi, 33, 381 (1969).

[11] J.A. Bragagnolo, C. Wright, K.W. Boer. Phys. Status Solidi A, 24, 147 (1974).

[12] А.С. Батырев, Р.А. Бисенгалиев, Н.В. Жукова, Б.В. Новиков, Э.И. Читыров. ФТТ, 45 (11), 1961 (2003).

[13] А.С. Батырев, Р.А. Бисенгалиев, Б.В. Новиков. ФТТ, 55 (4), 639 (2013)

[14] R. Boyn. Phys. Status Solidi, 29, 307 (1968).

Редактор А.Н. Смирнов 


\title{
Effects of ion bombardment in the spectra of edge photoconductivity and in the current-voltage characteristics of CdS crystals
}

A.S. Batyrev ${ }^{1}$, R.A. Bisengaliev', V.N. Goryaeva ${ }^{1}$, B.V. Novikov' ${ }^{2}$, E.V. Suyanova ${ }^{1}$

${ }^{1}$ Kalmyk State University

named after B.B. Gorodovikov, 358000 Elista, Russia

${ }^{2}$ St. Petersburg State University, 199034 St. Petersburg, Russia

\begin{abstract}
The effect of ion bombardment in air on the electrical and photoelectric properties of CdS crystals at the boiling point of liquid nitrogen $(T=77 \mathrm{~K})$ has been investigated. It is shown that the bombardment of crystals leads to a significant increase in the photosensitivity in the region of the absorption edge, as well as to an increase in their dark conductivity. At the same time, the quantitative changes in the dark conductivity significantly exceed the changes in the photosensitivity of all studied samples. The observed changes in the fine (excitonic) structure indicate the surface nature of the effect of ions on the semiconductor. The observed changes are associated with surface doping of the investigated semiconductors by donors using ion bombardment. The applied bombardment technique can be used for practical purposes in order to modify the electrical properties of semiconductors belonging to the $\mathrm{A}^{\mathrm{II}} \mathrm{B}^{\mathrm{VI}}$ compounds.
\end{abstract}

